\title{
Hybrid Artificial Immune System-firefly Algorithm Technique for Optimal DG Capacity and Operational Strategy in Distribution System
}

\author{
M S Yusof ${ }^{1}$, S R A Rahim ${ }^{1,2, *}$, M H Hussain ${ }^{1}$, S A Azmi ${ }^{1,2}$, A Azmi ${ }^{1}$, N Hashim ${ }^{1}$ \\ ${ }^{1}$ School of Electrical System Engineering, Universiti Malaysia Perlis, Malaysia \\ ${ }^{2}$ Centre of Excellence for Renewable Energy, Universiti Malaysia Perlis, Malaysia
}

Received September 6, 2019; Revised December 18, 2019; Accepted December 24, 2019

Copyright $\subseteq 2019$ by authors, all rights reserved. Authors agree that this article remains permanently open access under the terms of the Creative Commons Attribution License 4.0 International License

\begin{abstract}
This paper presents a study on hybrid optimization technique for optimal distributed generation (DG) capacity and operational strategy in distribution system. In this study, hybrid method namely Artificial Immune System-Firefly Algorithm (AISFA) is developed to determine the optimal size of the schemes respectively in the distribution system. The Firefly Algorithm (FA) which is a type of meta-heuristic algorithm is inspired by the blinking or flashing behaviour of fireflies that is embedded into Artificial Immune System (AIS) algorithm. The aim of this study is to develop the AISFA algorithm in order to improve the voltage profile and minimize losses of distribution system between the different operational strategy and types of DG. The types of DG include DG type 1 , DG type 2, and DG type 3 . The proposed technique was verified on IEEE 69-bus test system and the program was developed using the MATLAB programming software. The results showed a significant loss reduction in the line losses and voltage profile improvement has been obtained for optimal DG capacity and operational strategy in distribution system. From the simulation, the results were recorded in terms of the total losses and minimum voltage for the system. The results of the optimisation process of DG are utilized for the assistance of power system operators and planners. The power system planner can adopt the suitable sizes and locations from the obtained result for the planning of utility in term of economic and geographical consideration.
\end{abstract}

Keywords Artificial Immune System, Distributed Generation, Firefly Algorithm, Hybrid AISFA, Voltage Profile Improvement

\section{Introduction}

The power distribution network is one of the important parts of the power system. This is because it is the last part of power distribution to most customers such as industry, commerce and resident. Therefore, the distribution network must be kept customers in good quality power with acceptable voltage profile so power loss can be minimized. The introduction of schemes such as Distributed Generation (DG) plays an important role in the distribution system. The location and size of the scheme are critical because poor selection will have a negative impact on the power system.

Installation of DG is one of the acceptable and popular compensation schemes. However improper placement and sizing for DGs can cause the over-compensated or under-compensated phenomena[1]. With optimal placement and sizing of distribution and sizing of distributed generation or compensating capacitor or both of them, the maximum possible advantages could be obtained especially to improve the performance and to reduce losses in the system[2]-[8]. In order to increase the overall efficiency of power delivery in the distribution system, the loss reduction of $I^{2} R$ is very important to be considered.

The implementation of distributed generation (DG) involved an optimisation process in order to determine the optimal sizing of the DG. There are numerous optimisation techniques such as Stochastic Algorithm [9], Evolutionary Computation [10]-[12] ,Swarm Intelligence [13]-[15], Physical Algorithms [16], Immune Algorithms [17]-[19] and Neural Algorithms [20][21]. Nowadays, many researchers have turned their attention to meta-heuristic approach due to the increase of computation intelligence technologies [22]. The hybrid optimization technique provides potential benefits to the conventional 
optimization techniques.

This study presented the comparative study between types of distributed generation (DG) on voltage profile and loss minimization of distribution system. The purpose of this project is to propose an meta heuristic technique in order to improve the voltage profile and minimize losses of distribution system between the different types of DG. The types of DG include DG type 1, DG type 2, and DG type 3. The effectiveness of developed technique is tested on a test system, namely IEEE 69-bus distribution system [23]. The single line diagram for the test systems is shown in Figure A1. The artificial intelligence technique that will be used to improve voltage profile and minimize the losses of the DG is Hybrid AISFA. The software that will be used to perform this optimization technique is MATLAB software. The best 5 optimal locations within the 69-bus test system and the DG sizing will be obtained. Then, the results that are obtained between the different types of DG will be compared in terms of voltage profile and loss minimization and the best type of DG will be identified.

\section{Methodology}

The main purpose of this study is to reduce losses in distribution system using computational intelligence technique. In this study, a hybrid method which is the combination of Artificial Immune System (AIS) and
Firefly Algorithm (FA) is used as computational intelligent technique in order to find the optimal sizing of the scheme at a candidate location. Distributed generation (DG) is used in this study to install in distribution network in order to reduce losses in the distribution system.

Figure B1 shows the flowchart implementation of hybrid AISFA in order to find the sizing of DG in distributed generation and the method is tested in IEEE 69-bus distribution test system. Based on the flowchart in Figure B1, the initialization of bus and line data of IEEE 69-bus system is identified as a distribution system.

The hybrid AISFA is developed to find the optimal sizing of DG capacity in order to minimize losses in distribution system. The proposed method must be able to produce the minimum size of schemes as low as possible directly proportional to the reduction of losses in the distribution system. If the desired results are not acceptable, the hybrid AISFA needs to be checked and edited in term of initialized value and parameters. This step keeps being carried out until the desired result is acceptable. Results from the simulation for each proposed schemes are observed and analysed. The objective function is proposed to minimise active power loss shown in (1).

$$
f(x)=\min \left(\sum_{j=1}^{\text {line }} \text { Ploss }\right)
$$

The optimal size of DG is modeled by taking the output of DG as variable to be optimised for different types of DG as shown in Figure 1.

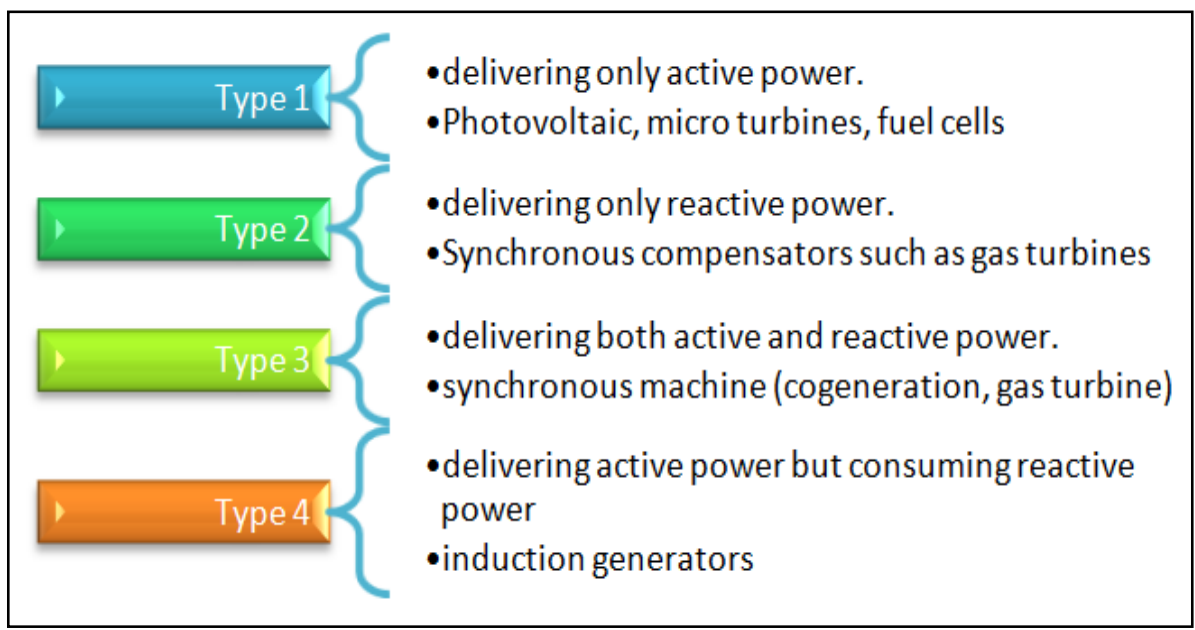

Figure 1. Types of DG 


\subsection{Proposed Hybrid Artificial Immune System-Firefly Algorithm (AISFA)}

The proposed AISFA technique is developed with an objective to reduce the distribution losses while considering the voltage constraint in the distribution system. Several studies have revealed that hybrid algorithm could minimise the disadvantages and improve efficient, faster and more robust [24][25]. The AISFA is established by integrating FA properties into the AIS algorithm. The AIS idea is used to describe the basic reaction of the immune system by being adaptive to antigen stimulation. This idea expresses that the only cells can identify antigens that will reproduced, whereas other cells are ignored. Once the antibody attach to the antigen, then activated and set apart into plasma cells or memory cells, the Clonal selection works on $\mathrm{T}$ cells and $\mathrm{B}$ cells in cell B [26]. Previously, B cell duplicates are formed and experience somatic hyper-mutation. The result acquired diversity in the population of $\mathrm{B}$ cells to plasma cells produce antibodies antigen-specific works for antigens [27]. After the cloning process, the coding will continue with FA properties which are determination of the light intensity of fireflies, attractiveness of fireflies and the movement of firefly to the brighter one. For implementation of the algorithm, the parameters; $\beta=0.2, \gamma=1, \alpha=0.25$ are used. Firefly algorithm has three specific procedures which are based on the behaviour of firefly [28]. The value of objective function can only be proportional to the brightness. In the FA, with a reduction in light intensity and attractiveness, the distance from the source increases, and the variation of the light intensity and attractiveness should be a monotonically reducing function. Distance $r$ varies with attractiveness via $\exp ^{[-\gamma r]}$. Then, the new solutions are evaluated will updated light intensity. The firefly attractiveness, $\beta$, Cartesian distance between any two fireflies $i$ and $j$, and the movement of firefly can be defined by (2), (3) and (4) respectively [1][29][30].

$$
\begin{gathered}
\beta=\beta_{0} \mathrm{e}^{-\gamma \mathrm{r}^{2}} \\
r_{i j}=\left\|x_{i}-x_{j}\right\|=\sqrt{\sum_{k=1}^{d}\left(x_{i, k}-x_{j, k}\right)^{2}} \\
x_{i}=x_{i}+\beta_{0} e^{-\gamma r^{2}}\left(x_{j}-x_{i}\right)+\alpha(\text { rand }-0.5)
\end{gathered}
$$

Next, the process is continuing with Artificial Immune System (AIS) which is mutation, evaluate fitness and add to properties, selection for next generation and convergence test. Convergence criteria are detailed by the difference of less than 0.0001 among the maximum and the minimum fitness. If the condition of convergence is not met, the procedure will be repeated until the condition of convergence is reached.

\section{Result and Discussion}

The five buses with lowest value of voltage magnitude, $\mathrm{V}_{\mathrm{m}}$ are observed for installation of DG. Based on Figure 2, bus $61,62,63,64$ and 65 are selected for installation of DG type 1 and DG type 2. Voltage magnitude for Bus 61 is $0.9124 \mathrm{pu}$, for bus 62 is $0.9121 \mathrm{pu}$, for bus 63 is 0.9117 , for bus 64 is 0.9098 and for bus 65 is 0.9092 .

Based on the results obtained from Table 1, by installing DG type 1 at bus 61 with the DG sizing of 1.8293 MW has the highest real power loss reduction with $62.98 \%$. The total reduction losses after compensation were $0.0833 \mathrm{MW}$ from $0.225 \mathrm{MW}$. The second highest real power loss reduction is bus 62 with $61.51 \%$ followed by bus 63 with $61.29 \%$, bus 64 with $56.84 \%$ and bus 65 with $48.89 \%$.

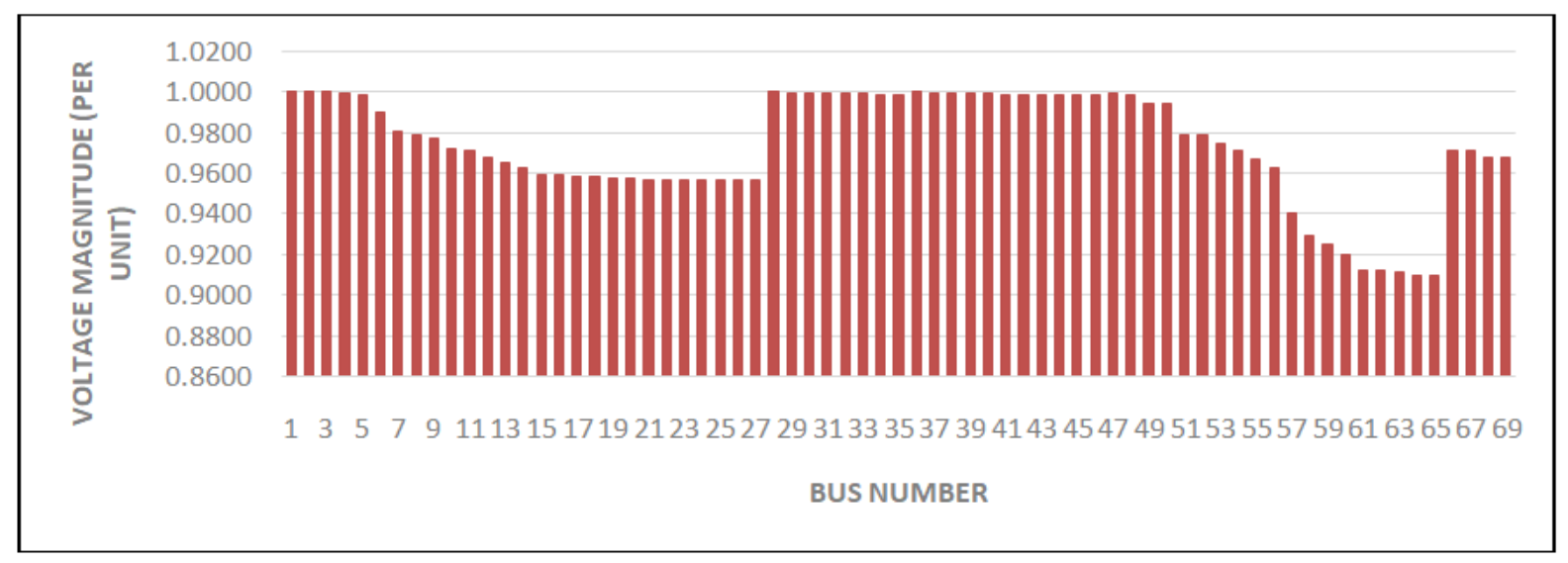

Figure 2. Graph of voltage magnitude vs bus number. 
Table 1. Results of Hybrid AIS with FA after installation of DG type 1

\begin{tabular}{cccccc}
\hline No & $\begin{array}{c}\text { Testing DG } \\
\text { on bus }\end{array}$ & $\begin{array}{c}\text { Best DG size } \\
\text { (MW) }\end{array}$ & $\begin{array}{c}\text { Total Real Power Loss before } \\
\text { compensation (MW) }\end{array}$ & $\begin{array}{c}\text { Total Real Power Loss after } \\
\text { compensation (MW) }\end{array}$ & $\begin{array}{c}\text { Real Power Loss } \\
\text { Reduction (\%) }\end{array}$ \\
\hline 1 & 61 & 1.8293 & 0.225 & 0.0833 & $62.98 \%$ \\
\hline 2 & 62 & 1.6167 & 0.225 & 0.0866 & $61.51 \%$ \\
\hline 3 & 63 & 1.8713 & 0.225 & 0.0871 & $61.29 \%$ \\
\hline 4 & 64 & 1.5359 & 0.225 & 0.0971 & $56.84 \%$ \\
\hline 5 & 65 & 1.1941 & 0.225 & 0.115 & $48.89 \%$ \\
\hline
\end{tabular}

Table 2. Results of Hybrid AIS with FA after installation of DG type 2

\begin{tabular}{cccccc}
\hline No & $\begin{array}{c}\text { Testing } \\
\text { DG on bus }\end{array}$ & $\begin{array}{c}\text { Best DG size } \\
\text { (MVar) }\end{array}$ & $\begin{array}{c}\text { Total Real Power Loss before } \\
\text { compensation (MVar) }\end{array}$ & $\begin{array}{c}\text { Total Real Power Loss after } \\
\text { compensation (MW) }\end{array}$ & $\begin{array}{c}\text { Real Power Loss } \\
\text { Reduction (\%) }\end{array}$ \\
\hline 1 & 61 & 1.2622 & 0.225 & 0.1522 & $32.36 \%$ \\
\hline 2 & 62 & 1.4935 & 0.225 & 0.1543 & $31.42 \%$ \\
\hline 3 & 63 & 1.396 & 0.225 & 0.1549 & $31.16 \%$ \\
\hline 4 & 64 & 1.3601 & 0.225 & 0.1621 & $27.96 \%$ \\
\hline 5 & 65 & 1.1088 & 0.225 & 0.1699 & $24.49 \%$ \\
\hline
\end{tabular}

Table 3. Results of Hybrid AIS with FA after installation of DG type 3

\begin{tabular}{ccccccc}
\hline No & $\begin{array}{c}\text { Testing } \\
\text { DG on } \\
\text { bus }\end{array}$ & $\begin{array}{c}\text { Best DG size } \\
\text { (MW) }\end{array}$ & $\begin{array}{c}\text { Best DG size } \\
\text { (MW) }\end{array}$ & $\begin{array}{c}\text { Total Real Power Loss } \\
\text { before compensation } \\
(\mathrm{MW})\end{array}$ & $\begin{array}{c}\text { Total Real Power Loss } \\
\text { after compensation (MW) }\end{array}$ & $\begin{array}{c}\text { Real Power Loss } \\
\text { Reduction (\%) }\end{array}$ \\
\hline 1 & 61 & 1.8649 & 0.945 & 0.225 & 0.0276 & $87.73 \%$ \\
\hline 2 & 62 & 1.8136 & 0.9198 & 0.225 & 0.0298 & $86.76 \%$ \\
\hline 3 & 63 & 1.745 & 0.8827 & 0.225 & 0.0332 & $85.24 \%$ \\
\hline 4 & 64 & 1.8023 & 0.9136 & 0.225 & 0.0443 & $80.31 \%$ \\
\hline 5 & 65 & 1.2929 & 0.6541 & 0.225 & 0.0685 & $69.56 \%$ \\
\hline
\end{tabular}

From the Table 2, by placing the DG unit at the bus 61 with the sizing of 1.2622 MVAR for DG type 2 has the highest real power loss reduction with $32.36 \%$. The total reduction losses after compensation were $0.1522 \mathrm{MW}$ from $0.225 \mathrm{MW}$. The second highest real power loss reduction is bus 62 with 31.42\% followed by bus 63 with 31.16\%, bus 64 with $27.96 \%$ and bus 65 with $24.49 \%$.

Next, from Table 3, by installing DG type 3 at bus 61 with the DG sizing of 1.8649 MW and 0.9450 MVAR has the highest real power loss reduction with $87.73 \%$. The total reduction losses after compensation were $0.0276 \mathrm{MW}$ from 0.225 MW. The second highest real power loss reduction is bus 62 with $86.76 \%$ followed by bus 63 with $85.24 \%$, bus 64 with $80.31 \%$ and bus 65 with $69.56 \%$.

Comparative studies have been conducted with respect to the different types of DG in order to highlight its strength in terms of its ability to achieve optimal solution as shown in Figure 3. The results show the percentage of reduction for installation of DG Type 3 managed to outperform the others with considerable percentages of loss reduction of $87.73 \%$ when located at ad Bus 61. It is also revealed that the proposed Hybrid AISFA has successfully reduced the system losses while improving the voltage profile. 


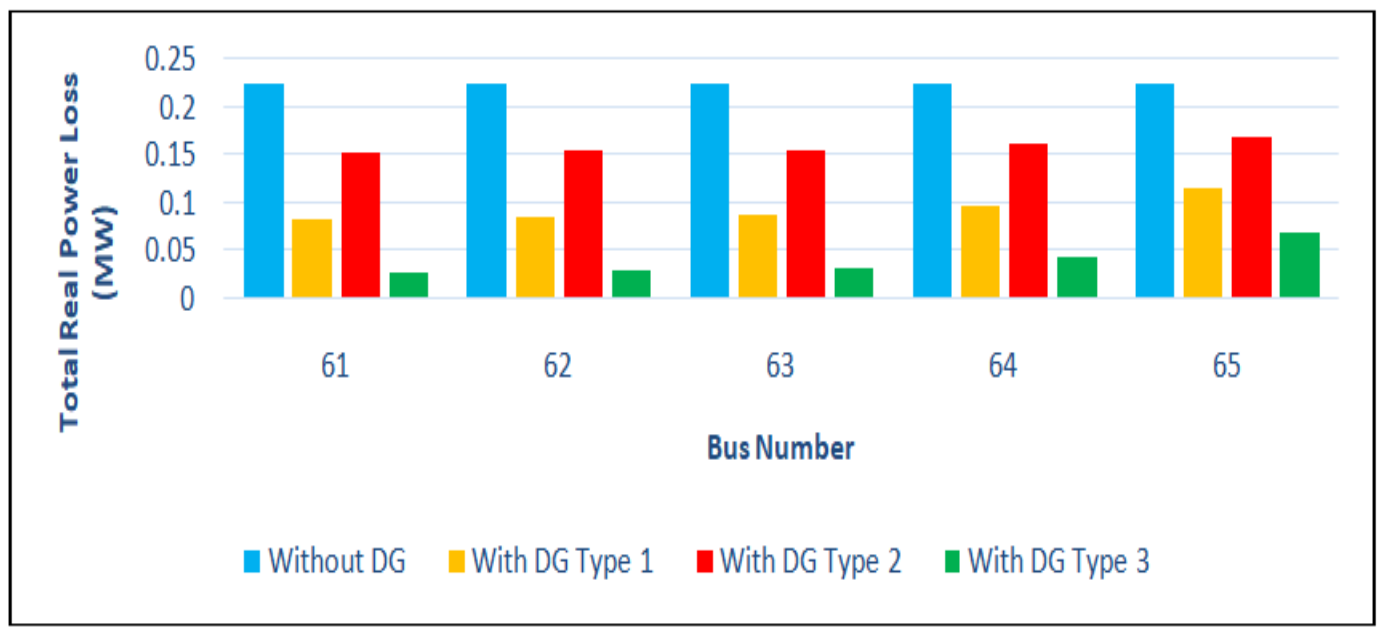

Figure 3. Results of Hybrid AIS with FA

\section{Conclusions}

In this study, the method has been proposed namely Hybrid Artificial Immune System-Firefly Algorithm (AISFA) where DG, one of the proposed compensation schemes is used. The proposed methods are verified on IEEE 69-bus distribution system. The five buses with lowest value of voltage magnitude $\left(\mathrm{V}_{\mathrm{m}}\right)$ were selected which are bus 61, 62, 63, 64 and 65. When the potential location has been identified, the Hybrid AISFA is designed with the objective of determining the size of DG in the radial distribution network. Then, different types of DG which are DG type 1, DG type 2 and DG type 3 provide the requirement result accurately and give good performance for solving sizing problem in the distribution system. The obtained results show that incorporating the schemes in the distribution system can decrease the total line power losses.
However, the installation of DG type 3 seems to have had a big impact in loss reduction compared to installation of DG type 1 and type 2 into the distribution system. Therefore, it can be concluded that the proposed methods are successfully applied for optimal allocation and sizing schemes in IEEE 69-bus test system.

\section{Acknowledgements}

The authors would like to acknowledge School of Electrical System Engineering, Universiti Malaysia Perlis for the financial support of this research and Ministry of Education Malaysia under the Fundamental Research Grant Scheme (FRGS) with project code: (Ref Code: FRGS/1/2019/TK07/UNIMAP/02/9). 


\section{Appendixes}

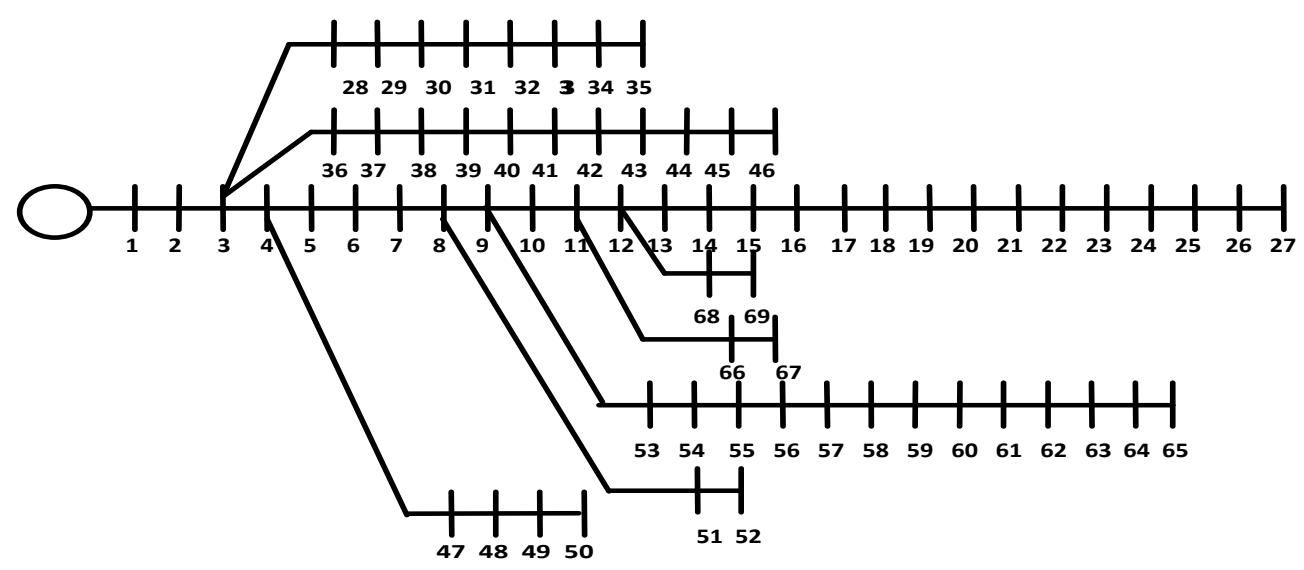

Figure A1. IEEE 69-Bus Distribution System

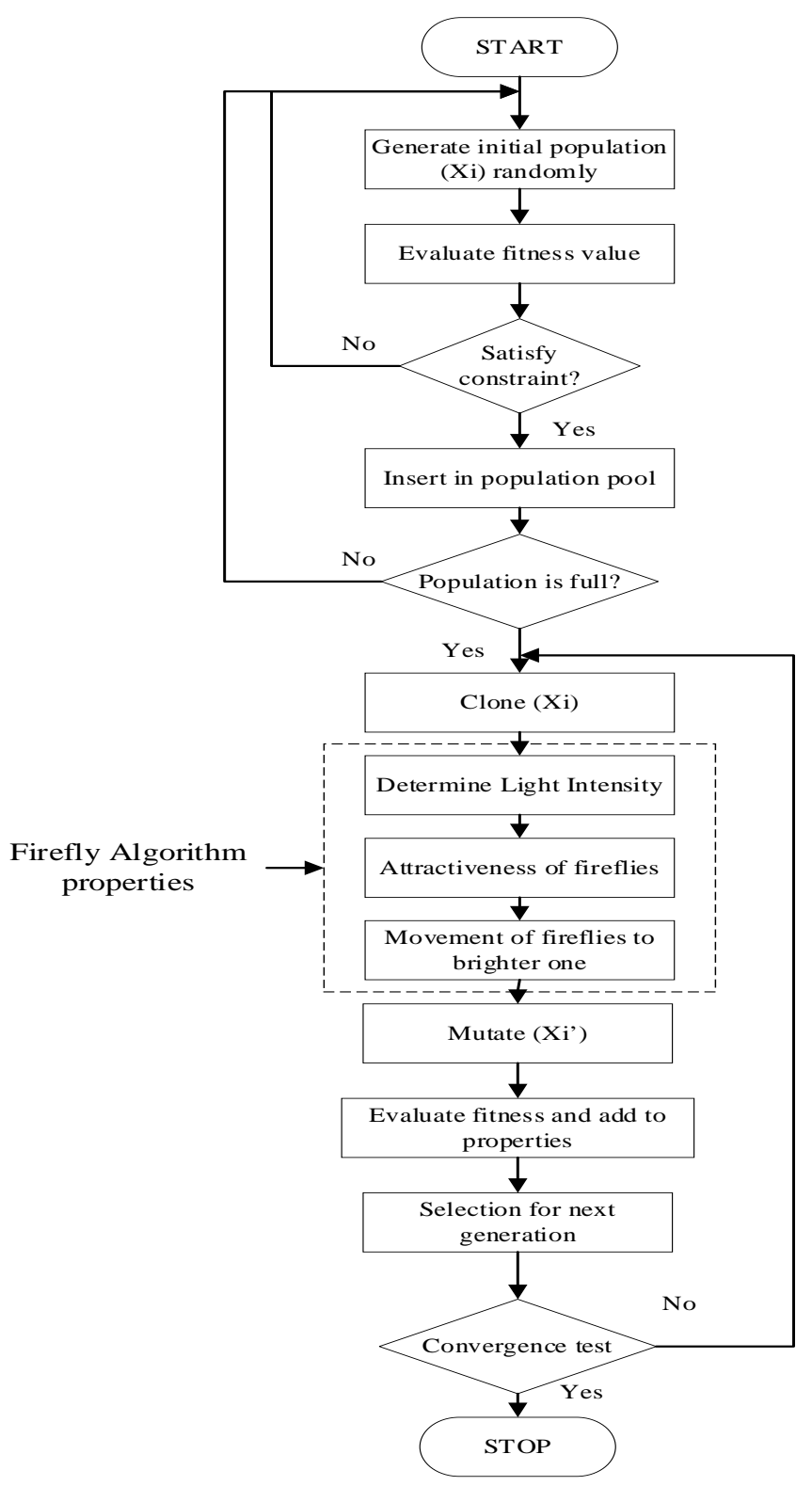

Figure B1. Flowchart for implementation of Hybrid AISFA 


\section{REFERENCES}

[1] S. R. A. Rahim, I. Musirin, M. M. Othman, and M. H. Hussain, "Effect of DG Installation in Distribution System for Voltage Monitoring Scheme,” Int. J. Electr. Comput. Energ. Electron. Commun. Eng., vol. 7, no. 12, pp. 520-525, 2013.

[2] Q. Kang, T. Lan, Y. Yan, L. Wang, and Q. Wu, "Group search optimizer based optimal location and capacity of distributed generations,” Neurocomputing, vol. 78, no. 1, pp. 55-63, 2012.

[3] H. Nasiraghdam and S. Jadid, "Load model effect assessment on optimal distributed generation (DG) sizing and allocation using improved harmony search algorithm,” in Conference on Smart Electric Grids Technology (SEGT), 2013, pp. 210-218.

[4] N. Rugthaicharoencheep and T. Langtharthong, "Reliability Improvement with Optimal Placement of Distributed Generation in Distribution System,” World Acad. Sci. Eng. Technol. Int. J. Electr. Sci. Eng., vol. 7, no. 10, pp. 394-398, 2013.

[5] M. M. Aman, G. B. Jasmon, A. H. A. Bakar, and H. Mokhlis, "A new approach for optimum simultaneous multi-DG distributed generation Units placement and sizing based on maximization of system loadability using HPSO (hybrid particle swarm optimization) algorithm," Energy, Jan. 2014.

[6] C. Nayanatara, J. Baskaran, and D. P. Kothari, "Hybrid optimization implemented for distributed generation parameters in a power system network,” Int. J. Electr. Power Energy Syst., vol. 78, pp. 690-699, 2016.

[7] E. Zio, M. Delfanti, L. Giorgi, V. Olivieri, and G. Sansavini, "Monte Carlo simulation-based probabilistic assessment of DG penetration in medium voltage distribution networks,” Int. J. Electr. Power Energy Syst., vol. 64, pp. 852-860, 2015.

[8] A. El-Fergany, "Study impact of various load models on DG placement and sizing using backtracking search algorithm," Appl. Soft Comput. J., vol. 30, pp. 803-811, 2015.

[9] A. Hadian and M. R. Haghifam, "Placement of DG with stochastic generation,” in 2010 IEEE PES Transmission and Distribution Conference and Exposition: Smart Solutions for a Changing World, 2010, pp. 1-7.

[10] K. Chellapilla and G. B. Fogel, "Multiple Sequence Alignment Using Evolutionary Programming," in Proceedings of the 1999 Congress on Evolutionary Computation-CEC99, 1999, pp. 445-452.

[11] D. B. Fogel, “What is evolutionary computation?,” IEEE Spectr., vol. 37, no. 2, pp. 26, 28-32, 2000.

[12] W. Banzhaf, "Evolutionary Computation and Genetic Programming,” in Engineered Biomimicry, 2013, pp. 429447.

[13] S. C. Chu, H. C. Huang, J. F. Roddick, and J. S. Pan, "Overview of algorithms for swarm intelligence," in
Lecture Notes in Computer Science (including subseries Lecture Notes in Artificial Intelligence and Lecture Notes in Bioinformatics), 2011, vol. 6922 LNAI, no. PART 1, pp. 28-41.

[14] J. Timmis, P. Andrews, and E. Hart, "On artificial immune systems and swarm intelligence,” Swarm Intell., vol. 4, no. 4, pp. 247-273, 2010.

[15] X.-S. Yang, “Swarm intelligence based algorithms: a critical analysis,” Evol. Intell., vol. 7, no. 1, pp. 17-28, 2013.

[16] R. Wattenhofer, "Physical algorithms," in Lecture Notes in Computer Science (including subseries Lecture Notes in Artificial Intelligence and Lecture Notes in Bioinformatics), 2010, vol. 6199 LNCS, no. PART 2, pp. 38-51.

[17] J. Al-Enezi, M. Abbod, and S. Alsharhan, "Artificial Immune Systems-models, algorithms and applications," Int. J. Res. Rev. Appl. Sci., vol. 3, no. May, pp. 118-131, 2010

[18] K. Trojanowski and S. T. Wierzchoń, "Immune-based algorithms for dynamic optimization,” Inf. Sci. (Ny)., vol. 179, no. 10, pp. 1495-1515, 2009.

[19] P. Jarosz and T. Burczyski, "Coupling of immune algorithms and game theory in multiobjective optimization," in Lecture Notes in Computer Science (including subseries Lecture Notes in Artificial Intelligence and Lecture Notes in Bioinformatics), 2010, vol. 6114 LNAI, no. PART 2, pp. 500-507.

[20] N. H. Hashim, T. K. A. Rahman, M. F. A. Latip, and I. Musirin, "Application of ANN to determine the OLTC in minimizing the real power losses in a power system," in National Power Engineering Conference, PECon, 2003, pp. 66-70.

[21] A. Heidari, V. G. Agelidis, and H. Zayandehroodi, "Reliability Worth Analysis of Distributed Generation Enhanced Distribution System Optimal Radial Basis Function Neural Network," in Power Engineering and Optimization Conference (PEOCO), 2013, pp. 641-646.

[22] T. G. Manjunath and A. Kusagur, "Analysis of Different Meta Heuristics Method in Intelligent Fault Detection of Multilevel Inverter with Photovoltaic Power Generation Source,” Int. J. Power Electron. Drive Syst., vol. 9, no. 3, p. 1214, 2019.

[23] M. E. Baran and F. F. Wu, "Optimal sizing of capacitors placed on a radial distribution system," IEEE Trans. Power Deliv., 1989.

[24] R. Syahputra and I. Soesanti, “An artificial immune system algorithm approach for reconfiguring distribution network," AIP Conf. Proc., vol. 1867, 2017.

[25] S. N. B. Z. Siti Rafidah Abdul Rahim, Syahrul Ashikin Azmi, Mohd Herwan Sulaiman, Muhamad Hatta Hussain, "a Study on Optimizing Techniques for the Sizing of Dg in Distribution System,” Electr. Energy Ind. Electron. Syst., no. December, pp. 1-5, 2009.

[26] X. S. Yang and X. He, "Firefly algorithm: recent advances and applications,” Int. J. Swarm Intell., vol. 1, no. 1, p. 36, 2013. 